\title{
Flipped versus Traditional Classroom Information Literacy Sessions: Student Perceptions and Cognitions
}

\author{
Torstein Låg* \\ UiT The Arctic University of Norway
}

\begin{abstract}
Teaching effectively with limited classroom time is a challenge for information literacy teachers. In the flipped classroom (FC) teaching model, information transmission teaching is delivered outside of class, freeing up class time for learning activities. I adopted the FC model in sessions that were previously taught using a traditional classroom (TC) model. The aim of this paper is to evaluate the FC model's relative impact on (1) student perceptions of usefulness and quality, and (2) student cognitions about the IL sessions.
\end{abstract}

Responses to evaluation forms from the TC model $(\mathrm{N}=65)$, were compared to those from FC model $(\mathrm{N}=78)$. Students judged usefulness and quality on two 4-point rating scales. Student cognitions were elicited with an open-ended question asking for suggestions for improvement and other comments. Responses to the latter were coded by an assistant blind to the conditions.

Ratings were near ceiling and similar for both conditions. Responses to the open-ended question revealed interesting trends. Students in the FC condition provided wordier comments, were more concerned with what they themselves did and could do, and with the subject matter of the session. Students in the TC condition were more concerned with how information was presented to them.

Results indicate that the FC teaching model is a viable alternative for IL sessions, and that it may encourage students to engage more with IL and their own learning process.

Keywords: information literacy, teaching, flipped classroom, active learning

\author{
*Contact: \\ Torstein Låg \\ UiT The Arctic University of Norway \\ E-mail: torstein.lag@uit.no
}




\section{Introduction}

Teaching information literacy (IL) effectively presents a number of challenges. One of them is making the most of limited teaching time, often in "one shot" sessions (Willson, 2012). In particular, allocating session time between covering material and engaging students in hands on activities to practice IL competencies is a persistent dilemma for IL teachers (Watson et al., 2013). Is it possible to increase time on student-centred IL learning activities, increasing students' workload and the effort required of them, while maintaining satisfaction and possibly increasing engagement? This study evaluates the use of a flipped classroom (FC) teaching model in an intermediate level IL session that was previously taught using a traditional classroom (TC) structure, by comparing student ratings and comments across the two conditions.

\section{Teaching for active learning}

While much teaching in higher education still relies on the plenary lecture (e.g. Norgesuniversitetet, 2015), evidence is mounting that instructional methods that encourage active learning lead to measurable increases in student performance (Freeman et al., 2014; Michael, 2006; Prince, 2004). Thus, even though we as IL teachers are constantly tempted to pack sessions to bursting with all the information we want our students to absorb, they are more likely to retain something useful if we employ active learning instructional methods.

Prince (2004) defines such methods as those that "...engages students in the learning process. (...) active learning requires students to do meaningful learning activities and think about what they are doing." (p. 223). There are a number of different pedagogical approaches that fit under the active learning umbrella (see Bishop, 2014, p. 14-28 for an overview). Various forms of collaborative learning and various forms of problem or inquiry based learning are prominent examples.

It is possible, however, to employ active learning methods without strictly adhering to the philosophies of any of these approaches. One recently popular instructional manoeuvre that relates more eclectically to the approaches mentioned above is the flipped or inverted classroom (Bergmann \& Sams, 2012; Lage, Platt, \& Treglia, 2000). While its proponents will emphasise different aspects, the essence of the flipped classroom model is this: Moving the teacher-centred, information-transmission teaching out of, and prior to, the classroom session, typically using video, in order to make room for more student-centred learning activities in the classroom session.

\section{The present study}

In this study, I evaluated an attempt to improve intermediate-level IL sessions using the FC teaching model. Student evaluations from sessions using the TC model were compared to sessions using the FC model, in effect creating a quasi-experimental control group design. The aim was to assess the FC model's relative impact on (1) student perceptions of usefulness and quality, and (2) student cognitions about the IL sessions.

\section{Methods}

\section{Setting and participants}

At UiT The Arctic University of Norway, we offer two separate psychology tracks. One is a 6-year clinical program with integrated practicums, the other a 5-year general psychology bachelor/master program. The session studied in the present project came in the students' 
second and third year, respectively. All students had been introduced to IL in their first year of studies. They had practiced basic searches, familiarised themselves with scholarly sources, and practiced using sources in their own written work. In the presently studied sessions, we focused on search, building on what the students already knew, but progressing by introducing "real" reference databases, controlled search vocabularies, and building complex searches using operators.

65 students ( 43 clinical track and 22 bachelor, in 2014/2015) participated in two TC sessions. 78 students ( 46 clinical track and 32 bachelor, in 2015/2016) participated in the FC sessions. No demographic data are available.

\section{The sessions}

The TC sessions were $3 \times 45$ minutes, of which the first 60 minutes were used for explaining controlled vocabularies and operators through lecturing, and demonstrating their use through example searches. In the remaining 75 minutes, students worked in pairs on exercises, one of which was to build a search for the topic of a written assignment. Plenary discussions of possible solutions were interspersed throughout. Prior to the session, all I had done was to spend about 5 minutes on the first day of class for the courses that these sessions were a part of, saying "hello" and briefly explaining what we would be doing in the sessions.

For the FC sessions, the expository teaching was compressed and recorded in 4 short videos with a total playing time of 25 minutes. Videos were made available two weeks prior to the sessions, along with a written explanation and instruction. Also two weeks prior to the session, I met with the students in another teacher's session, and spent 15 minutes explaining the rationale behind, and the processes involved in an FC session. Importantly, I highlighted that it was essential they actually watched the videos beforehand, and that they would not be able to participate unless they had. In the IL session itself, we spent 15 minutes on a brief introduction and an opportunity for students to ask questions based on their viewing of the videos. The remaining 120 minutes were spent on student exercises and plenary discussions, identical to those in the TC sessions.

\section{Data collection and analyses}

Student perceptions and cognitions were collected with an evaluation form. Two questions were simple rating questions. One asked students to rate the usefulness of the session on a 4-point scale ranging from Not useful to Very useful, the other to rate the quality of the teaching on a 4point scale ranging from Poor to Very good. The third question was an open-ended freeresponse question asking students: "Is there anything you think we should have done differently, or do you have any other comments?" When handing out the form and asking students to fill it in, I followed the same procedure in all sessions, drawing their attention to the open-ended question, because that is where I find the feedback that helps guide my teaching.

Responses to rating questions were aggregated and compared across conditions. Comments made in response to the open-ended question were tallied and measured for word count. They were then temporarily isolated from the rest of the data, sorted in random order, and processed by a research assistant naïve to the conditions and purpose of the study. Her instructions were to identify recurring themes in student responses, and to label each response with the labels based on these themes. Subsequently, comments were "reunited" with the rest of the data, the number of responses labelled with each recurring theme were tallied, and comments were compared across conditions. 


\section{Results}

\section{Ratings of usefulness and quality}

Ratings of usefulness in the TC condition $(M=3.95, S D=0.28)$ were similar to those in the FC condition $(M=3.92, S D=0.27)$. An independent samples Mann-Whitney $\mathrm{U}$ test confirmed equal distributions ( $p=.25)$. Ratings of quality in the TC condition $(M=3.89, S D=0.31)$ were similar to, but slightly lower than, those in the FC condition $(M=3.79, S D=0.41)$. Distributions were again equal $(p=.12)$.

\section{Student comments}

The proportions of students making a comment to the free-response question were similar in the two conditions ( $\mathrm{TC}=72.3 \%, \mathrm{FC}=78.2 \% ; \chi^{2}=0.67, p=.41$ ). However, the average word count per comment was higher in the FC condition $(M=17.9, S D=11.6)$ compared to the TC condition $(M=12.5, S D=10.3 ; t(108)=2.54, p=.012)$.

Three frequently recurring themes in student comments were Learning (about session instructiveness or student attainment of learning), Presentation (about how information was conveyed to students), and Searching/Databases (about the content of the session, specifics relating to searching, controlled vocabularies, operators or databases).

The proportion of comments about learning were similar in both conditions (TC $=27.7 \%$, $\mathrm{FC}=29.5 \% ; \chi^{2}=0.04, p=.83$ ). However, when reading these comments, it seemed students in the TC condition were more concerned with how information was presented and received. Indeed, the proportion of comments relating to Presentation were somewhat higher in the TC condition $(27.7 \%)$ compared to the FC condition $\left(14.8 \% ; \chi^{2}=2.73, p=.10\right)$. Interestingly, students in the FC condition were seemingly more concerned with the actual content of the session, i.e. matters relating to searching and databases. This impression was to some extent borne out by the tally of search-related comments; there were slightly more in the FC condition $(24.6 \%)$ compared to the TC condition $\left(14.9 \% ; \chi^{2}=1.54, p=.22\right)$.

A subjective impression based on my own reading of the comments seemed to indicate that students in the FC group were more concerned with what they themselves did in the session and would do with what they had learned. This was, however, not a theme identified by the research assistant. above.

Table 1 presents a few selected comments illustrating several of the trends identified

Table 1. Selected student comments (translated from Norwegian)

\begin{tabular}{|c|c|}
\hline Condition & Comment \\
\hline \multirow{2}{*}{ Traditional } & $\begin{array}{l}\text { "...and I was given all the info I needed and this info was presented in a good } \\
\text { way." }\end{array}$ \\
\hline & $\begin{array}{l}\text { "Good and useful information, but at times the pace was too fast. " } \\
\text { "As long as you upload the recipes for the different searches, this will be top } \\
\text { notch." }\end{array}$ \\
\hline \multirow{2}{*}{ Flipped } & $\begin{array}{l}\text { "...I've made some great notes (...) that I will definitely use in future } \\
\text { searches." }\end{array}$ \\
\hline & "Good that we got to search on our own topic. I was itching to try once I \\
\hline
\end{tabular}


realised how to use PsycINFO."

"Teacher was good at circulating and helping everyone. Could have spent more time on complex searches."

\section{Discussion}

This study compared student evaluations of intermediate-level IL sessions taught with either a traditional (TC) or a flipped classroom (FC) teaching model. Students rated session usefulness and quality to be the same, regardless of instructional method. Analyses of comments in response to an open-ended question revealed interesting trends: Students in the FC condition had more to say overall than students in the TC condition. And, while students in the TC condition tended to be more concerned with how information was conveyed to them, students in the FC condition made more comments about the specifics of the session content, i.e. searching, operators and databases.

Results from rating questions indicate that students perceive FC IL sessions to be both useful and of high quality, and comparable to TC sessions. While student perceptions do not always correspond to learning measured more objectively, perceptions of course quality may influence the learning approach students adopt (Diseth, 2007), and student perceptions of usefulness and quality are, arguably, important in their own right.

Interpreting the pattern of results from student comments is not straightforward. However, wordier comments, more comments about the content of the session, fewer comments about how information was conveyed by the teacher, and more comments concerning what the students did and would do, are at least consistent with the idea that flipping the IL classroom leads students to engage deeper with the topics of the session, and to think more about how they can apply the competencies they have practiced in their own studies.

\section{Conclusion}

Flipping the IL classroom certainly makes room for more student-centred learning activity. Students in this study were quite satisfied with the FC model, despite it requiring more effort on their part compared to traditional teaching. Their comments seemed to indicate that students engage in more IL-related thinking in the FC condition compared to the TC condition. Thus, the FC model appears to be a viable alternative to traditional teaching for IL sessions. It represents a convenient way for IL teachers to move further towards teaching for active learning, without compromising student satisfaction.

Thanks to Kristine Farstad for assistance with processing student comments. 


\section{References}

Bergmann, J., \& Sams, A. (2012). Flip your classroom: Reach every student in every class every day. Eugene, OR: International Society for Technology in Education.

Bishop, J. L. (2014). A controlled study of the flipped classroom with numerical methods for engineer [PhD thesis]. Available from Proquest Dissertations \& Theses Global database (UMI No. 3606852). Retrieved from http://search.proquest.com/docview/1492991096?accountid=17260

Diseth, Å. (2007). Approaches to learning, course experience and examination grade among undergraduate psychology students: Testing of mediator effects and construct validity. Studies in Higher Education, 32(3), 373-388. http://dx.doi.org/10.1080/03075070701346949

Freeman, S., Eddy, S. L., McDonough, M., Smith, M. K., Okoroafor, N., Jordt, H., \& Wenderoth, M. P. (2014). Active learning increases student performance in science, engineering, and mathematics. Proceedings of the National Academy of Sciences, 111(23), 8410-8415. http://dx.doi.org/10.1073/pnas.1319030111

Lage, M. J., Platt, G. J., \& Treglia, M. (2000). Inverting the classroom: A gateway to creating an inclusive learning environment. Journal of Economic Education, 31(1), 30-43. http://dx.doi.org/10.1080/00220480009596759

Michael, J. (2006). Where's the evidence that active learning works? Advances in Physiology Education, 30(4), 159-167. http://dx.doi.org/10.1152/advan.00053.2006

Norgesuniversitetet. (2015). Digital tilstand 2014. Norgesuniversitetets skriftserie. No. 1/2015. Retrieved from https://norgesuniversitetet.no/files/dt_2014_250615.pdf

Prince, M. (2004). Does active learning work? A review of the research. Journal of Engineering Education, 93(3), 223-231. http://dx.doi.org/10.1002/j.2168-9830.2004.tb00809.x

Watson, S. E., Rex, C., Markgraf, J., Kishel, H., Jennings, E., \& Hinnant, K. (2013). Revising the "oneshot" through lesson study: Collaborating with writing faculty to rebuild a library instruction session. College \& Research Libraries, 74(4), 381-398. http://dx.doi.org/10.5860/crl12-255

Willson, R. (2012). Independent searching during one-shot information literacy instruction sessions: Is it an effective use of time? Evidence Based Library and Information Practice, 7(4), 16. http://dx.doi.org/10.18438/b85323 